\title{
How to Define Illegal Price Manipulation
}

\author{
By Albert S. Kyle and S. Viswanathan*
}

Draft: January 14, 2008

The term "illegal price manipulation" is difficult to define. Current U.S. law does not explicitly define it. The finance and economics literature uses the term "manipulation" in an imprecise manner. This paper proposes that a trading strategy not be classified as "illegal price manipulation" unless the violator's intent is to pursue a scheme that undermines economic efficiency both by making prices less accurate as signals for efficient resource allocation and by making markets less liquid for risk transfer. Since price effects are market-wide, we treat the terms "price manipulation" and "market manipulation" as synonyms. Our definition applies equally to financial and commodities markets.

* Kyle: University of Maryland, Robert H. Smith School of Business, 4433 Van Munching Hall, College Park, MD 20742-1815, akyle@rhsmith.umd.edu. Viswanathan: Duke University, Fuqua School of Business, One Towerview Drive, Durham, NC 27708, viswanat@mail.duke.edu. We thank our discussant Alex Edmans for his comments.
"Pricing accuracy" means something different from the term "market efficiency." Pricing accuracy measures the precision with which prices provide signals to encourage efficient resource allocation. Market efficiency refers to the difficulty of making trading profits on the basis of available information. In a market which is about to be cornered, high prices are consistent with market efficiency because they accurately forecast the probability of the corner, but not consistent with pricing accuracy because prices are providing signals to mis-allocate resources.

Illegal price manipulation includes corners and squeezes, pump-and-dump manipulation, and failure to make required disclosures. It excludes routine hedging, market making, and speculation. Speculation includes both trading on private information and trading to provide a 
risk-bearing service to others. Illegal behavior such as front-running or fraudulent price quotations designed to influence cash-settled prices is not manipulation, since effects are not marketwide.

The definition of illegal price manipulation based on undermining both the informational and transactional role of financial markets stands in sharp contrast to unsatisfactory definitions based on the routine rational exploitation of market power or private information necessarily part of a Bayesian Nash equilibrium. Benign strategies include restricting the quantity traded to avoid price impact (Albert S. Kyle (1985), Kyle (1989)), using mixed strategies which involve both buying and selling to minimize transactions costs (F. Douglas Foster and S. Viswanathan (1994), Kerry Back and Shmuel Baruch (2003)), bluffing (Jos van Bommel (2003)), inter-temporal market depth arbitrage (Fischer Black (1995)), and "punching the close" (Kyle (2007)). Our definition distinguishes between these harmful and benign strategies.

Our definition is consistent with both U.S. case law and the recent UK and EU principles- based codes of conduct. Although failure to make required disclosures or making false disclosures may be illegal manipulation, the concept of illegal manipulation includes non-deceptive strategies such as setting up a public cartel to control supplies of a manipulated commodity.

In the rest of this paper, we discuss how imperfect competition, private information, and network externalities motivate our definition of price manipulation; show that traditional types of illegal price manipulation, such as corners and squeezes and pump-and-dump schemes, are consistent with our definition; discuss how our definition is consistent with the legal approach to manipulation in the US and Europe; and discuss enforcement issues.

\section{What is Illegal Price}

\section{Manipulation?}

Definitions of price manipulation have long reflected a tension between subjective approaches ("the smell test")and more scientific approaches based on economic efficiency (see Adam Smith (1776)). In this paper, we propose that a trading strategy not be defined as illegal price manipulation unless it simultaneously undermines both 
pricing accuracy and market liquidity. When a farmer increases his plantings of corn because corn futures prices are high at the time of planting, he relies on the price as a signal to allocate resources. When a grain merchant chooses to hedge a greater fraction of his inventory because market liquidity improves, he relies on the liquidity of the market to influence the manner in which risks are allocated. Similar illustrative examples can be given for financial markets. When a corporation invests more because its stock price is high, even if it does not need to issue new equity to do so, it relies on the signalling role of prices.

Our proposed definition of illegal price manipulation is derived from the subtle way in which market power, private information, and network externalities interact in speculative markets. It is a well-established textbook result that in perfectly competitive markets with no "externalities", competition among traders leads to an efficient allocation of resources. Speculative markets are neither neither perfectly competitive nor free of externalities. Large traders are not perfect competitors; they restrict the quantities they trade to reduce price impact. Because of positive network externalities, organized markets become more liquid as more traders who demand liquidity choose to participate.

Traders seeking speculative profits engage in costly effort to acquire private information and generate two different types of externalities as a result. First, when suppliers of liquidity believe that more trading on private information is taking place, they supply less liquidity, thus reducing market liquidity for all traders. Private information is like a negative externality on traders who demand liquidity. Second, informed traders typically push prices in a direction consistent with their private information, incorporating their information into prices, and creating a positive externality for those who use prices as signals. Since demand for trading is somewhat elastic, increased market liquidity may improve economic efficiency. Further, such deep, liquid markets tend to be transparent. This protects customers from being induced to trade at unfavorable prices with better informed dealers, and discourages dealers from spending large sums in a socially wasteful effort to acquire less informed customers with whom they can trade profitably (Marco Pagano and Ailsa Roell (1996)). 
The theoretical finance and economics literature simultaneously models how the depth of the market and the informativeness of prices are determined by markets in which liquidity traders demand transactional services, large informed traders with market power trade on the basis of private information, and market makers supply liquidity. In this trading game, market makers intermediate between liquidity traders who lose money on average and the informed traders make money on average (Jack Treynor (1971)). Liquidity traders are hedgers who are willing to pay for a risk-transfer service or naively overconfident traders who expect to make profits but will actually lose money on average; informed traders are sophisticated entities like hedge funds who make money on average. Kyle (1985) and Kyle (1989) show how large traders with private information restrict the quantities they trade in the process of maximizing profits and drive prices in a direction consistent with their private information, increasing the informativeness of prices. Anat Admati and Paul Pfleiderer (1988)and Foster and Viswanathan (1990) discuss how increased liquidity attracts more trading volume and thus liquidity tends to pool in one marketplace as traders create positive trading externalities for one another.

If the demand for liquidity is large and elastic, while the value of prices as signals is very small, there may be an inefficiently high level of social resources devoted to producing private information to generate speculative profits and inefficiently low levels of market liquidity. Mandatory disclosure of corporate accounting data, or government funded disclosure of crop information may make prices more information and markets deeper, while discouraging private production of information of little social value. Since intentional violations of disclosure requirements have the reverse effects, these violations satisfy our definition of illegal price manipulation.

\section{Traditional Examples of Illegal Manipulation}

Both corners and squeezes, as well as pumpan-dump schemes, are illegal price manipulation.

In a corner or squeeze, the manipulator obtains a dominant position in the asset sufficient to make it costly for traders with short positions to acquire the asset for the purpose of 
making delivery (see Kyle (1984)). The cornered or squeezed asset becomes expensive relative to close substitutes and expensive for nearby relative to deferred delivery dates. Market participants inefficiently postpone consumption, inefficiently hurry production, and inefficiently move the commodity through time and space. If market participants anticipate ex ante that the risk of being cornered or squeezed has increased, this extra source of adverse selection induces them to lessen market liquidity. As markets become less liquid, it becomes more difficult for a perpetrator to corner the market without being noticed. If the market believes that regulatory enforcement can prevent corners and squeezes, then market liquidity can be higher than it would be otherwise. Thus, corners and squeezes both interfere with the signalling role of prices and tend to erode market liquidity, satisfying our definition of illegal price manipulation.

A corner or squeeze is intrinsically a "repo squeeze", in that the successful perpetrator must finance his long position in such a way that the squeezed asset is not loaned to traders who potentially have short positions. A corner or squeeze can thus be diagnosed by finding in- tentional use of "off-the-street" financing. If a large bullish trader acquires more than one hundred per cent of the supply of an asset without using off-the-street financing, then speculators who believe the asset is overvalued can sell it short, maintain the short position for as long as necessary at little cost, and make a profit if they are correct. The large bullish trader need have little effect on prices and may even encourage market depth to increase if other traders believe he is simply a large liquidity trader. Thus, large long positions unaccompanied by off-the-street financing are generally not illegal price manipulation.

In 1979-1980, the Hunt brothers of Texas cornered the market for silver bullion by making massive purchases in both cash and futures markets. Prices sky-rocketed from about $\$ 7$ per ounce to more than $\$ 40$ per ounce. As market participants began to worry that a corner was in progress, silver bullion began to trade at a significant premium over silver coins, and silver refineries increased production. Market liquidity dried up, trading volume fell precipitously, and risk transfer was thus impaired. Nearby futures prices began to trade at premiums for for- 
ward dates when deliveries to the Hunt brothers were expected to exceed available bullion supplies. The scheme collapsed when the exchanges limited the ability of the Hunts to take delivery, the Fed discouraged speculative lending, and refiners created massive supplies of new bullion.

In a "reverse" corner or squeeze, the perpetrator makes it difficult for the market to absorb supplies of the manipulated asset by flooding the market with collateral and driving down prices.

It is difficult to implement a reverse corner or squeeze of a financial asset, since all that is required to "store" a financial asset is access to credit, which is usually widely available. Reverse corners and squeezes are more realistic possibilities for expensive-to-store commodities like oil and electricity.

In a pump-and-dump manipulation scheme, the perpetrator first acquires a large long position, then publishes false information to induce market participants to push prices up by buying the asset, and finally liquidates his own long position at a profit. The inefficiently high prices lead to a misallocation of resources by inducing firms to make inefficiently optimistic investments. False information erodes liquidity by un- dermining the credibility of truthful releases of information. Publication of false information is a necessary component of this type of illegal manipulation, and this makes enforcement conceptually possible, if not easy.

\section{Consistency with Legal}

\section{Approach to Manipulation}

Consistent with Adam Smith's (1776) view that actions motivated by self-interest can benefit the common good, the legal system in market economies recognizes that market participants often trade for selfish motives that are socially beneficial, not intrinsically illegal. The legal system recognizes that "manipulation" or "market abuse" tends to undermine the social benefits that markets provide, but it has been difficult for legal systems to describe specifically which practices constitute illegal manipulation. In the US, the law prohibits manipulation but leaves it to the courts to define it on a case-by-case basis. The UK and the EU have recently proposed a principles-based description of prohibited manipulative practices.

Case-law in the US implements a four-part test involving ability intent, causation, and arti- 
ficiality (Philip Johnson (1981) for a discussion). The Indiana Farm Bureau case (1982) decision is consistent with our approach, but it discusses the concept of "artificial price" in a somewhat circular manner:

"To determine whether an artificial price has occurred one must look at the aggregate forces of supply and demand.... When the aggregate forces of supply and demand bearing on the particular market are all legitimate, it follows that the price will not be artificial. On the other hand, when a price is affected by a factor which is not legitimate, the resulting price is necessarily artificial."

Our definition avoids this circularity. A price becomes artificial when a trader with the ability to corner, intentionally causes a corner which creates an artificial price by making prices inaccurate and reducing market liquidity.

The concept of a Bayesian Nash equilibrium can be used to model strategic speculative trading among imperfect competitors with private information. The finance and economics literature often describes a market participant's optimal trading strategy as "manipulating" the beliefs of other traders, e.g., when an informed trader makes a profit because he trades is such a manner that market mistakenly believes he might have not private information. For all traders, it is not illegal manipulation if such trading either increases the informativeness of prices or makes markets more liquid.

In a Bayesian Nash equilibrium, an informed trader who acquires private information may "bluff" by acting in a manner opposite to his information as part of his optimal strategy (Foster and Viswanathan (1994), Back and Baruch (2004) and Archisman Chakraborty and Bilge Yilmaz (2004)). Back and Baruch (2004) show that randomizing between buying and selling may be an optimal way for a trader to extract as much liquidity from the market as possible Traders may spread true rumors of the form "buy, I bought" or "sell, I sold." (van Bommel (2003)) as part of a strategy to maximize trading profits based on private information. Although the academic literature frequently describes these strategies as "manipulation", these strategies are not illegal manipulation in our sense because they may allow prices to be better signals or allow markets to provide more liquidity. 
Our position is that bluffing, randomizing, adding noise, or spreading true rumors is not necessarily illegal manipulation is consistent with the opinion in the Indiana Farm Bureau case that "seeking the best price" is not necessarily manipulative:

"Seeking the best price for ones commodity is a legitimate, indeed critical, price-creating force in the futures markets that in-and-of-itself cannot be the basis of an inference of manipulative intent."

Thus, for example, a large trader has no obligation to sell at a particular reasonable price to a buyer who places a large, potentially destabilizing, order to buy. Similarly, taking delivery is not necessarily illegal manipulation.

Since taking delivery is not necessarily illegal manipulation, strategies economically and financially equivalent to taking delivery are not necessarily illegal manipulation either. In a cashsettled derivatives contract, an outcome financially and economically equivalent to making or taking delivery can be achieved by replacing expiring long or short positions with purchases or sales in the cash market at the moment of expiration. Praveen Kumar and Duane Seppi (1992) confusingly refer to this as a manipulative strategy called "punching the close." Kyle (2007) explains why an upward price spike which occurs when traders with long positions replace positions while traders with short positions do not does not indicate that the long illegally manipulates prices upward, but rather that the short who does nothing pushes prices up by using cash settlement to liquidate his position.

Self-regulation faces two intrinsic incentive problems. First, an organized exchange may not be disinterested, in that members of internal regulatory committees may have trading positions. Second, exchanges may have a dubious incentive to label as "illegal manipulation" pro-competitive practices which allow rival exchanges to compete more effectively for the exchange's order flow. For example, organized exchanges, as a tactic for making it harder other exchanges from competing for order flow by offering cash-settled clones, have an incentive to discourage mimicking delivery by treating punching the close as illegal price manipulation.

In contrast to the United States, where case law does not explicitly define illegal price manipulation, the Financial Services Authority and 
the European Union have moved to a more explicit principles-based code of conduct. The FSA code of conduct is based on three principles: misuse of information, false or misleading impression and market distortion. similarly, the European Union directive on insider trading and market manipulation (EU Directive 2003(6)EC) requires member states to disallow the inappropriate dissemination of insider information, the misuse of insider information and market manipulation.

\section{Trade-Based Manipulation and Enforcement Issues}

Daniel Fischel and David Ross (1991) argue that distinguishing between illegal manipulative trades and trades by legitimate informed or hedging investors is difficult and hence suggest that the " concept of manipulation should be abandoned altogether." Their argument does not apply well to corners and squeezes, where the ability to observe off-the-street financing makes enforcement possible. It also does not apply to pump-and-dump manipulation, since it may be possible for an enforcement agency to track down the source of false disclosures which are part of such a scheme. The argument is potentially relevant for what Franklin Allen and Douglas Gale (1992) call "trade based manipulation," i.e., schemes which involve trading only, with no off-the-street financing and no false disclosures. Trade-only strategies present present two challenges. First, there is the intellectual problem of determining whether a scheme undermines both pricing accuracy and market depth. Second, there is the enforcement problem of distinguishing an illegal scheme from a legal one which might manifest itself in identical behavior, differing only perhaps in private information in the mind of the perpetrator.

Itay Goldstein and Alexander Guembel (2007) describe a scheme in which a predatory short-seller massively sells short the shares of a company which needs to raise capital to finance good investment opportunities, drives down prices, induces the market to believe that the firm's investment opportunities are bad and hence not to finance the good investments. According to our definition, this scheme should be classified as illegal price manipulation because it obviously makes prices less accurate and less obviously erodes market liquidity by introduc- 
ing as an additional source of adverse selection, the possibility that a good company will perish as a result of predatory short-selling. An enforcement problem occurs because this predatory scheme looks similar to a socially valuable scheme in which the short-seller knows that the firm's over-hyped investment opportunities are really bad and short-sells the stock in a manner which improves economic efficiency by inducing an uninformed market not to fund bad investment opportunities.

Another class of examples can be classified as "market depth arbitrage." Kyle (1985) presents a model where in equilibrium, market depth must be constant because, if it is not, a trader can make large profits inconsistent with equilibrium by trading very aggressively either to add noise to prices or to make prices very accurate (see also Black (1995)). Such strategies are not illegal manipulation because they tend to increase market liquidity, at least during some trading periods, protecting naive traders who might otherwise trade at times of low liquidity.

Related to these strategies is so-called "predatory trading" (see Markus Brunnermeier and Lasse Pedersen (2005)), defined as intentionally heavy buying or selling which influences prices so as to flush out positions of traders who do not have enough capital to keep their positions financed in the face of adverse price moves . This is different from non-manipulative but illegal front-running because the predator is assumed not to have a legal obligation to avoid trading based on conjectures about the other traders' positions. Conceptually, it is difficult to prove that such strategies worsen both allocative efficiency and market depth. From an enforcement perspective, it is difficult to distinguish predatory trading from market depth arbitrage or ordinary speculation.

Thus, with regard to trade-based manipulation, it may be difficult or impractical for the legal system to define and enforce such schemes as illegal price manipulation.

\section{Conclusion}

We have argued that "illegal price manipulation" occurs only when the two fundamental roles of prices in financial markets are distorted - allocational efficiency that relates to market informativeness and transactional efficiency that relates to market liquidity. Our definition is con- 
sistent with US case law and UK and EU codes

of conduct. It rules out corners and squeezes, as well as pump-and-dump schemes. It allows bluffing, randomizing, spreading true rumors, and punching the close. It recognizes that illegal trade-based manipulation is difficult both to define and to prosecute.

\section{References}

Smith, Adam. 1776, "The Wealth of Nations," edited by Edward Cannan, New York: Modern Library.

Admati, Anat, and Paul Pfleiderer. 1988, "A Theory of Intraday Patterns: Volume and Price Variability," Review of Financial Studies, 1: 3-40.

Allen, Franklin, and Douglas Gale. 1992, "Stock Price Manipulation," Review of Financial Studies, 5: 503-529.

Back, Kerry, and Shmuel Baruch. 2004, "Information in Securities Markets: Kyle meets Glosten and Milgrom," Econometrica, 72: 433-465.

Black, Fischer. 1995, "Equilibrium Exchanges," Financial Analysts Journal, May-
June, 23-29

Brunnermeier, Markus, and Lasse Pedersen. 2005, "Predatory Trading," Journal of Finance, 60(4): 1825-1863.

Chakraborty, Archisman, and Bilge Yilmaz. 2004, "Manipulation in Market Order Models," Journal of Financial Markets, 7: 187-206.

European Union - Directive 2003(6)EC of the European Parliament and of the Council, 28th January 2003, Official Journal of the European Union.

Financial Services Authority, The Code of Market Conduct, FSA Handbook, Release 64, April 2007.

Fischel, Daniel, and David Ross. 1991, "Should the Law Prohibit "Manipulation" in Financial Markets?" Harvard Law Review, 105(2): 503-553.

Foster, F. Douglas, and S. Viswanathan. 1990, "A Theory of Interday Variations in Securities Markets, The Review of Financial Studies, 3 (4): 593-624. 
Foster, F. Douglas, and S. Viswanathan. 1994, "Strategic Trading With Asymmetrically Informed Traders and Long-Lived Information, Journal of Finance and Quantitative Analysis," 29: 499-518.

\section{Goldstein, Itay, and Alexander Guembel.} Forthcoming. 2007, "Manipulation and the Allocational Role of Prices," Review of Economic Studies.

Hayek, Frederich. A. 1945, "The Use of Knowledge in Society," The American Economic Review, 35 (4): 519-530.

in re Indiana Farm Bureau Coop. Ass'n, [1982-1984 Transfer Binder] Comm. Fut. Law. Rep. (CCH) P 21,796, 27, 288, n.2. (CFTC Dec. 17, 1982)).

Johnson, Philip M. 1981, "Commodity Market Manipulation," Washington and Lee Law Review, 38: 725-732.

Kumar, Praveen, and Duane J. Seppi. 1992, "Futures Manipulation with 'Cash Settlement."' Journal of Finance, 47: 14851502

Kyle, Albert S. 1984, "A Theory of Futures
Market Manipulation," In: Anderson, R.W. (editor), The Industrial Organization of Futures Markets, Lexington Books, Lexington MA.

Kyle, Albert S. 1985, "Continuous Auctions and Insider Trading", Econometrica, 53(6): 1315-1335.

Kyle, Albert S. 1989, "Informed Speculation with Imperfect Competition," The Review of Economic Studies, 56 (3): 317-355.

Kyle, Albert S. 2007, "Cash Settlement, Price Manipulation and the MillerModigliani Theorem," University of Maryland working paper.

Pagano, Marco and Ailsa Roell. 1996, "Transparency and Liquidity: A Comparison of Auction and Dealer Markets with Informed Trading," Journal of Finance, 51 (2): 579-611.

Treynor, Jack (as Bagehot). 1971, "The Only Game in Town, 22: 12-14.

van Bommel, Jos. 2003, "Rumors", Journal of Finance, 58: 1499-1520. 